\title{
Organizational Culture and Technological Innovation Adoption in
}

\section{Private Hospitals}

\author{
Luu Trong Tuan \\ National University of Ho Chi Minh City, Vietnam \\ E-mail: luutrongtuan@hcm.fpt.vn \\ Sundar Venkatesh \\ Asian Institute of Technology (AIT), Thailand
}

\begin{abstract}
This paper portrays an empirically grounded theory research on the impact of organizational culture on technological innovation adoption in 8 private hospitals in Vietnam. It identifies the dimensions of organizational culture underlying technological innovation adoption, namely cause vision, organizational structure compound, support mechanisms, and innovation stimulators, as well as highlights the fashion in which these dimensions operate will either activate or inhibit technological innovation.
\end{abstract}

Keywords: Organizational culture, Technological innovation adoption, cause vision, Organizational structure compound, Support mechanism, Innovation stimulator, Grounded theory, Multiple case study

\section{Introduction}

Hospital managers have looked upon technology as a strategic momentum in hospital development (Ramakrishnan, 2005; McDonald and Srinivasan, 2004; Rauner and Heidenberger, 2002). They also realize the correlation between technological innovations and hospital performance ( $\mathrm{Li}$ and Collier, 2000). Organisations and leaders try to create an institutional framework in which innovation will be accepted as fundamental cultural norms in the midst of technological and other changes. Researchers such as Ahmed (1998), Robbins (1996), and Pheysey (1993) have highlighted the significance of organisational culture in this setting. Organisational culture appears to have an influence on the degree to which innovation are stimulated in an organisation. Given the importance of the topic, there is a need for a deeper look into the nature of organizational culture and to explore its relationship to technological innovation adoption.

In some private hospitals, action is taken to stimulate innovation. The appropriate steps may have been taken, such as involving medical staff in decision making process, recruiting and appointing medical staff with innovative traits, setting standards for work performance and giving regular feedback, but innovation is still thwarted in some way. The culture of an organisation may be a contributing factor in the extent to which innovation occurs in an organisation (Judge et al., 1997; Tesluk et al., 1997; Tushman and O'Reilly, 1997; Johnson, 1996). The mismatches between current organisational culture and the demands of innovation may lead to a clash situation. This leads to the question:

What dimensions of organisational culture have an influence on technological innovation adoption in private hospitals?

The purpose of this article is to present, by means of a model, the dimensions of organisational culture which influence the degree of technological innovation adoption in a private hospital.

\section{Literature review}

\section{Organizational Culture}

Organizational culture is defined by Deshpandé and Webster $(1989$, p. 4) as “... the pattern of shared values and beliefs that help individuals understand organizational functioning and thus provides them with norms for behavior in the firm." This notion of culture is similar to the view that culture is an organizational trait manifested in the shared values and beliefs of its members (Hofstede, 1998; Trice and Beyer, 1993).

Furnham and Gunter (1993) summarise the functions of organisational culture as internal integration and coordination. Based on a literature study of the functions of organisational culture, internal integration can be depicted as the bonding of new members in the organisation, forming the boundaries of the organisation, the feeling of identity among personnel and commitment to the organisation. The coordinating function refers to creating a competitive edge, making sense of the environment in terms of acceptable behaviour and social system stability (which is the social glue that binds the organisation together) (Martins, 2000). 
Schein's (1985) model describes the levels of organisational culture, namely artifacts, values and basic assumptions and their interaction. Schein's model is criticised for not addressing the dynamic role of assumptions and beliefs in creating and changing organisational culture (Hatch, 1993).

Against this background and the work of Schein (1985), Martins (1987) developed a model to depict organisational culture based on the typical ideal organisation and the importance of leadership in creating an ideal organisational culture. Martins' model is based on the interaction between the organisational sub-systems (goals and values, structural, managerial, technological and psycho-sociological sub-systems), the two survival functions, namely the external environment (social, industrial and corporate culture) and the internal systems (artifacts, values and basic assumptions), and the dimensions of culture. The dimensions of culture encompass the following (Martins, 1987, 1997):

- Mission and vision (determines personnel's understanding of the vision, mission and values of the organisation and how these can be transformed into measurable individual and team goals and objectives).

- External environment (determines the degree of focus on external and internal customers and also employees' perception of the effectiveness of community involvement).

- Means to achieve objectives (determines the way in which organisational structure and support mechanisms contribute to the effectiveness of the organisation).

- Image of the organisation (focuses on the image of the organisation to the outside world and whether it is a sought-after employer).

- Management processes (focuses on the way in which management processes take place in the organisation. It includes aspects such as decision making, formulating goals, innovation processes, control processes and communication).

- Employee needs and objectives (focuses on the integration of employees' needs and objectives with those of the organisation as perceived by employees/personnel).

- Interpersonal relationships (focuses on the relationship between managers and personnel and on the management of conflict).

- Leadership (focuses on specific areas that strengthen leadership, as perceived by personnel).

This model is a comprehensive model which encompasses all aspects of an organisation upon which organisational culture can have an influence, and vice versa. This model can thus be used to describe organisational culture in an organisation and therefore be employed as background to determine which dimensions of organisational culture influence the degree of innovation in organisations.

\section{Innovation in Organisations}

West and Farr (1990) define innovation as follows: "the intentional introduction and application within a role, group or organization of ideas, processes, products or procedures, new to the relevant unit of adoption, designed to significantly benefit the individual, the group, organization or wider society". The context in which a new idea, product, service or activity is implemented apparently determines whether it can be regarded as an innovation within that specific context (Martins, 2000).

In the research under discussion innovation can be defined as the implementation of a new and possibly problem-solving idea, practice or material artifact (e.g. a product) which is regarded as new by the relevant unit of adoption and through which change is brought about (Martins, 2000).

The concept of innovation in the context of this research (determining which dimensions of organisational culture influence innovation) can be illustrated as in Figure 1.

Organisational culture appears to be a critical factor in the success of any organisation. Successful organisations have the capacity to absorb innovation into the organisational culture and management processes (Syrett and Lammiman, 1997; Tushman and O'Reilly, 1997). According to Tushman and O’Reilly (1997), organisational culture lies at the heart of organisation innovation.

The fundamental elements of organisational culture (shared values, beliefs and behaviour expected of members of an organisation) influence innovation in two ways:

1) Through socialisation processes in organisations, individuals learn what behaviour is acceptable and how activities should function. Norms develop and are accepted and shared by individuals. In accordance with shared norms, individuals will make assumptions about whether innovative behaviour forms part of the way in which the organisation operates (Chatman (1991) and Louis (1980) both cited in Tesluk et al., 1997). 
2) The basic values, assumptions and beliefs become enacted in established forms of behaviours and activity and are reflected as structures, policy, practices, management practices and procedures. These structures and so on impact directly on innovation in the workplace, For example, by providing resource support to pursue the development of new ideas (Tesluk et al., 1997). In this way individuals in organisations come to perceive what is considered valuable and how they should act in the workplace.

Organisational culture affects the extent to which innovative solutions are encouraged, supported and implemented. A culture supportive of innovation encourages innovative ways of representing problems and finding solutions, regards innovation as both desirable and normal and favours innovators as models to be emulated (Lock and Kirkpatrick, 1995).

\section{Research methodology}

This study adopted a case research method, which is considered a particularly useful method for research in the business field (Yin, 2002; Buchanon, Iyer, and Karl, 1999). Using the multiple case study design allowed us to explore the linkages between organizational culture and technological innovation adoption in private hospitals in Vietnam. Other researchers who have utilized and benefited from this approach include Tellis (1997) and Herriott and Firestone (1983).

A study intended to capture the dynamic linkages between organizational culture and technological innovation adoption must be designed to explore richness while simultaneously being able to capture patterns across hospitals. Case-based research provides the richness, but cannot effectively identify the patterns. Our research objectives lend themselves best to a grounded theory methodological approach (Glaser and Strauss, 1967). By this, pattern of linkages is discovered from observational data and in-depth interviews in a systematic manner, rather than by quantitatively testing hypotheses.

Data was gathered from eight private hospitals in Vietnam on which overview data are provided in Table 1. The hospital categorization in Table 1 was based on research findings rather than a priori information. The reason for selecting these hospitals was the degree of cooperation extended by these hospitals during the research work and the trusting relationship between the author and respondents in these hospitals through snowball sampling approach (Robson, 1993).

Grounded theory approach through case research was preferred over quantitative method since the questionnaire survey approach did not offer profound insights into the hospital practices. To minimize research bias we combined observation, interview and desk research. The information was gathered by conducting multiple in-depth interviews with 72 individuals from various levels in these hospitals, observation during hospital visits, and by referring to hospital annual reports and internal documents. The data was collected between March 2009 and December 2009 and updated prior to writing this paper.

As a follow up to the interviews with the directors of each of these hospitals, a literature review was conducted to further identify pattern of linkages between organizational culture and technological innovation adoption. The issues and concepts identified in the literature review were used to develop the data collection approach including the interview guides.

The main source of data collection in this research was in-depth interviews. The interview guide used open-ended questions, as many researchers (e.g., Travers, 2001; Patton, 1987) prefer this approach for its power to produce rich and original data. In each case, the questions were structured to elicit information about dimensions of organizational cutlure linked to technological innovation adoption. Interview guides were updated from questions that evolved and new dimensions of organizational culture linked to technological innovation adoption identified during each interview. As new questions were added, person previously interviewed were recontacted to elicit responses to the new questions.

Moreover, during observation visits at hospitals, informal conversational interviews were conducted with operations-level employees to supplement and verify the information obtained during the formal interviews. Patton (1987) identified this as an appropriate way to increase the salience of information that emerges from the immediate context and to obtain information pertinent to a particular situation. During interviews, notes were taken and tape-recorders were used only with the interviewees' permission.

Reliability and validity were essential concerns in this study. Both Denzin and Lincoln (2003) and Guion (2002) have argued that establishing the validity of a qualitative research method requires implementing a triangulated evaluated design. In this research, two types of triangulation were applied: methodological triangulation, adtoped by using multiple methods of data capture, and data triangulation, using a variety of data sources. 


\section{Findings and discussion}

The advantage of selecting grounded theory as the methodology for this study is two-fold. First it assists in analyzing qualitative data. Second, it helps develop a theoretical account that not only facilitates discussion, but is grounded in the data collected. Thus theory is developed from data, rather than testing existing theories (Martin and Turner, 1986). Based on our observations and in-depth interviews noted above, we now advance and discuss four categories or dimensions. These addresses: (1) cause vision; (2) organizational structure compound; (3) support mechanisms; and (4) innovation stimulators.

First Dimension: Cause Vision

An innovation strategy is a strategy that promotes the development and implementation of new products and services (Robbins, 1996). Covey (1993) claims that the origin of innovation lies in a shared vision and mission, which are focused on the future.

Observations and desk research showed that all directors of the hospitals imparted technological innovation into their vision and mission. Interviews with medical staff in the hospitals including heads of departments, both clinical and subclinical, also demonstrated that most of the heads of departments shared this vision with their directors referring to technological innovation as a crucial means of medical treatment quality improvement. Some hospital directors referred to technology innovation as a tool to enhance hospital reputation and brand image and increase the credibility of its marketing effort whereas some hospital directors referred to patients as customers in the competitive environment.

As highlighted in CIMA Study Text (1996), the vision and mission of an innovative organisation are also customer- and market-oriented, focusing on solving customers' problems among other things.

However, the director of the hospital $\mathrm{H} 4$, emphasized that what $\mathrm{H} 4$ members are doing are contributions to themselves, patients, and society: "Our hospital has been trying to adopt new medical treatment technologies, but the most important thing is our medical staff's awareness of benefits of technological innovation adoption to themselves, patients and society."

The director's perspective was shared by almost all of medical staff at $\mathrm{H} 4$ during the interviews: "The director always tells us doctors to look at what patients complain about since it is where innovation arises."

Behind the director's view is cause related marketing defined as "strategic positioning and marketing tool that links a company or a brand to a relevant social cause or issue, for mutual benefit." (Pringle and Thompson, 1999).

Interviews with medical staff of low management levels in the hospitals $\mathrm{H} 3$ and $\mathrm{H} 6$ demonstrated that they didn't see clear goals in the concept of innovation, let alone technological innovation. What they had to do everyday as they expressed was to try to fulfil their routine responsibilities. Most of them referred to technological innovation as top-management's business, and would learn to use new technology when it came to their department.

A different observation, however, was encountered at the hospitals $\mathrm{H} 2, \mathrm{H} 4$, and $\mathrm{H} 7$ where every employee was encouraged to make change, whether minor or major, considered rewarding, as expressed by a doctor working at H4: "I have made more contributions here than in my last place. The director always tells me to search for new technology, whether it is in treatment or management scope, which is beneficial to patients and makes H4 distinctive."

Judge et al. (1997) describe successful innovation as chaos within guidelines; in other words top management prescribes a set of strategic goals, but allows personnel great freedom within the context of the goals.

Organisational goals and objectives reflect the priorities and values of organisations and as a result may promote or hamper innovation (Arad et al., 1997). Hall (cited in Arad et al., 1997) found that personal and organisational goals that accentuate quality rather than effectiveness enhance the levels of innovation.

\section{Second Dimension: Organizational Structure Compound}

Organisational culture has an influence on the organisational structure and operational systems in an organisation (Armstrong, 1995). The structure appears to highlight certain values which have an influence on the promotion or restriction of innovation in organisations.

In the innovation literature, much has been written about the structural characteristics of organisations and according to Arad et al. (1997) and the CIMA Study Text (1996) a flat structure, autonomy and work teams will 
promote innovation, whereas specialisation, formalisation, standardisation and centralisation will inhibit innovation.

As for the impact of organisational culture on a structure that supports innovation, values like flexibility, freedom and cooperative teamwork will promote innovation. On the other hand, values like rigidity, control, predictability, stability and order (mostly associated with hierarchical structures) will hinder innovation (Arad et al., 1997). All above discussion on such aspects of organizational structure as flexibility, freedom and collaboration leads to our conversion of the term into organizational structure compound since these aspects behave like the atoms of a chemical compound, both firmly bonding to one another (collaboration) and retaining their identities and distintive properties (flexibility and freedom).

Most medical staff at the hospitals H3, H5, and H6 voiced that the notion of technological innovation pertained to upper middle management level upwards who are decision makers. Observations and interviews demonstrated that doctors and nurses outside management functions were reluctant to touch constraints such as time, budget, and innovation outcomes as a doctor at the hospital H6 expressed: "I don't think I can work innovatively if I find around me only constraints."

Also at H6, another doctor even showed negative attitude towards the way the hospital promoted and implemented technological innovation: "I have some technologically innovative ideas that can be applicable in this hospital, but I also know that it is none of my business. Ideas for the most part come from top management."

Freedom as a core value in stimulating innovation is manifested in autonomy, empowerment and decision making. This implies that personnel are free to achieve their goals in an automatic way within guidelines (described as "chaos within guidelines" by Judge et al. (1997)). Personnel therefore have the freedom to do their work and determine procedures as they see fit within the guidelines provided. Management should also believe in personnel and encourage them to be more innovative by allowing them more freedom, in other words empowering them instead of controlling them (Judge et al., 1997, p. 76).

The literature survey revealed that the degree to which employees have freedom and authority to participate in decision making in solving problems determines the level of empowerment, which is positively related to the level of innovation in an organisation (Arad et al., 1997, p. 4).

The speed of decision making can also promote or inhibit innovation. Tushman and O'Reilly (1997, p. 117) claim that cultural norms which lead to quick decision making (e.g. that speed is important and that the work rate is fast) should promote the implementation of innovation.

It was the case in several hospitals that there were a number of individual innovators but only a few innovative bondings. It could be found that there were varying speeds of technology innovation adoption in different departments in the hospitals as encountered at the hospital H3: "We have been applying this hospital management software for 6 months, but find it does not work well. Administration department and clinical departments are reluctant to collaborate."

On the contrary, the director at the hospital H4 encouraged collaboration in innovative groups: "When an individual comes up with a new idea on technological change, she or he automatically becomes project manager and leader of innovation team. She or he is also entitled to invite team members she or he can work well with. Normally the idea generator opens door for participants and this culture continues."

Co-operative teams are identified by some researchers as having an influence on the degree to which innovation take place in organisations. Well-established work teams which allow for diversity and individual talents that complement one another should promote innovation (Arad et al., 1997). Cross-functional teams which encourage social and technical interaction between developers and implementers can improve and promote innovation. Another important aspect is that team members should be able to trust and respect one another, understand one another's perspectives and style of functioning, solve differences of opinion, communicate effectively, be open to new ideas and question new ideas. Such effective teamwork is partly based on team members' skills and abilities and partly on the shared values within the group (e.g. values about shared trust and solving differences) (Tushman and O'Reilly, 1997).

Among the researched hospitals, the hospitals $\mathrm{H} 1, \mathrm{H} 2, \mathrm{H} 4, \mathrm{H} 7$ and $\mathrm{H} 8$ proved to be more successful in technological innovation adoption due to rich communication between top management and medical staff as well as between individuals and heads of departments. Interviews with medical staff of the other hospitals revealed that it was lack of communication, especially trust, that led to hesitation and even apprehension of new idea generation. 
An organisational culture that supports open and transparent communication, based on trust, will have a positive influence on promoting innovation (Barret, 1997; Robbins, 1996). Teaching personnel that disagreement is acceptable, since it offers the opportunity to expose paradoxes, conflict and dilemmas, can promote openness in communication. At the same time personnel must feel emotionally safe to be able to act innovatively and should therefore be able to trust one another, which in turn is promoted by open communication. An open-door communication policy, including open communication between individuals, teams and departments to gain new perspectives, is therefore necessary to create a culture supportive of innovation (Frohman and Pascarella, 1990; Samaha, 1996).

\section{Third Dimension: Support mechanisms}

Observations and interviews showed that most hospitals announced their recognition of innovations at meetings of hospital and department levels. The hospitals $\mathrm{H} 2, \mathrm{H} 4$ and $\mathrm{H} 7$ even put on bulletin-boards names of individuals and teams who made innovation contributions. In parallel to innovation recognition, individuals and teams received adequate rewards as shown in desk research data and through interviews. However, interviews also revealed that most doctors paid more attention to mental rewards than physical rewards, as expressed by some doctors at the hospital H4: "We don't learn and apply new technology for money, but for patients and for our knowledge. However, the director says we deserve a pay rise or bonus for our contribution to the patients and the hospital. He even says we need to knock the door of his office and ask for this if he forgets it."

Interviews disclosed that a few hospitals didn't provide adequate resources for innovation adoption. However, the contrast could be found at H4: "When we manage to convince the director about our innovation project, his question always is what the best support is you need from the hospital for the success of the project."

Most hospitals solely provided technologies required for innovation, but failed to spot an essential element of innovation - creative and innovative people. Such hospitals as H2, H4, and H7 even set up alliances with innovative experts from Medical Universities such as Dr. T., who is famous for information technology innovation in medicine.

Support mechanisms should be present in the culture of an organisation to create an environment that will promote innovation. The literature study revealed that rewards and recognition and the availability of resources, namely time, information technology and innovative people, are mechanisms that play this role.

Behaviour that is rewarded reflects the values of an organisation. If innovative behaviour is rewarded, it will become the general, dominant way of behaving (Arad et al., 1997). The problem is that many organisations hope that personnel will think more innovatively and take risks, but they are rewarded for well-proven, trusted methods and fault-free work. Personnel should also be rewarded for risk taking, experimenting and generating ideas. Intrinsic rewards like increased autonomy and improved opportunities for personal and professional growth may support the innovation process (Shattow, 1996; Amabile and Gryskiewicz (1987) and Kanter (1983) cited in Arad et al., 1997). It is also important to reward individuals as well as teams (Tushman and O'Reilly, 1997). Management should be sensitive to which methods of reward and recognition will inspire personnel in their specific organisation to be more innovative (Tushman and O'Reilly, 1997).

In some hospitals, interviews disclosed that organizational culture didn't favor creativity and innovation as reflected in individual attitudes towards innovation: "We don't want to make any change, because it means we have more work to do."

An organisational culture that promotes innovation should allow employees time to think innovatively and experiment (Shattow, 1996). In organisations where innovation are encouraged, personnel are, for example, allowed to spend 15 percent of their time on generating new ideas and working on their favourite projects. Emphasis on productivity and downsizing, which leads to more pressure on employees to work harder, is not conducive to innovation in organisation (Filipczak, 1997).

Observations and interviews showed that most individuals took advantage of information technology to collaborate. The hospitals H1, H4 and H8 even set up videoconferencing for discussion with regional or overseas experts in the specific field of technology.

Information technology as a support mechanism is an important resource for successful innovation (Shattow, 1996). In organisations where it is part of the culture to use computer technology such as the Internet and intranet to communicate and exchange ideas, the chances of innovation taking place are improved (Bresnahan, 1997; Khalil, 1996).

\section{Fourth Dimension: Innovation Stimulators}

Values and norms that encourage innovation manifest themselves in specific behavioural forms that promote or inhibit innovation. 
Doctors and nurses at the hospitals H1, H2, H4 and H7 reported that they were encouraged by top management to improve medical treatment quality, particularly by means of technological innovation. As a doctor at H4 stated: "The director always says you can call me any time especially in two cases: you find out a problem in this hospital or you have a new idea."

However, interviews also indicated that several departments of the hospitals, especially finance departments, appeared not to support an individual's or a team's new idea if they once failed, as explained by a few doctors at the hospitals H3 and H6: "We just do the way we do now. We used to make change and failed. And the management does not seem to back us when we suggest a change."

The way in which mistakes are handled in organisations will determine whether personnel feel free to act innovatively. Mistakes can be ignored, covered up, used to punish someone or perceived as a learning opportunity (Brodtrick, 1997). Tolerance of mistakes is an essential element in the development of an organisational culture that promotes innovation. Successful organisations reward success and acknowledge or celebrate failures, for example, by creating opportunities to openly discuss and learn from mistakes (Tushman and O'Reilly, 1997).

A few doctors at the hospitals H3 and H6 explained: "Our technological innovation, to some extent, improved treatment quality; however, it did not yield the margin the finance managers expected. Looking upon this as a risk, we are reluctant to try another new idea."

Some doctors even admitted that they didn't know how to deal with finance managers' questions such as "Do your team think this new technology will produce more profit than the current technology?" However, as doctors explained, they came up with this new idea just because they found this new technology could bring patients better treatment.

Taking risks and experimenting are behaviours that are associated with innovation. A culture in which too many management controls are applied will inhibit risk taking and consequently innovation (Judge et al., 1997). The assumption that risks may be taken as long as they do not harm the organisation will not encourage personnel to be innovative by experimenting and taking risks (Filipczack, 1997, p. 37). It is important that a balance should be reached in the degree to which risk taking is allowed. This can be achieved by spelling out expected results, assigning the responsibility of monitoring and measuring risk taking to someone in the organisation, creating a tolerant atmosphere in which mistakes are accepted as part of taking the initiative, regarding mistakes as learning experiences, and assuming that there is a fair chance of risks being successful.

Except the hospital H4, researched hospitals didn't show apparent competitiveness for technological innovation. H4's director always encouraged departments: "Why don't you try to put your names, your departments' names on the bulletin-boards of technological innovators so that everybody, especially your patients, can recognize?" Medical staff at $\mathrm{H} 4$ added that as they brought to the meetings the conflicts between departments, the director always challenged: "If your two departments seem to compete for the similar technological innovation, why don't you make alliance with each other? Why don't your department and finance department sit back and compromise? Why does finance department not look at less physical profit and more medical benefit whereas department of cardiology tries to reduce the down time through use of this technology to produce more profit?"

Research by Nÿstrom (1990) indicates that the most innovative departments in an organisation regard competitiveness as an important aspect of their culture. According to Read (1996, p. 226), competitiveness in organisations has shifted to the creation and assimilation of knowledge. In creating a culture of competitiveness managers should reach out to internal and external knowledge, encourage debating of ideas, create an environment in which constructive conflict will lead to information flow, support projects based on information flow and actively manage the choice of organisational design.

Tolerance of conflict and handling conflict constructively are values that support innovative behaviour in organisations (Robbins, 1997; Judge et al., 1997). When there is conflict between different ideas, perceptions and ways in which information is processed and evaluated, the process of handling conflict should be handled constructively to promote innovation. Understanding different individual thinking styles and training personnel in the process of constructive confrontation will create a culture supportive of innovation.

Four dimensions of organizational culture that influence technological innovation adoption are summarized in a model in Figure 2.

\section{Concluding remarks}

The model grounded in this research highlights the dimensions of organizational culture that play a role in promoting and implementing technological innovation. The research examined how the patterns between a 
dimension of organizational culture and medical staff's technological innovative behaviors emerge. It also demonstrated that the way in which these dimensions, namely cause vision, organizational structure, support mechanisms, and innovation stimulators, operate will either support or inhibit technological innovation. The eight-case research design overcame the disadvantages of studying too wide a variety of health-care industries and technologies, yet provided sufficient diversity to explore patterns among hospitals with different organizational cultures and technological innovative capacities.

\section{References}

Ahmed, P. K. (1998). Culture and climate for innovation. European Journal of Innovation Management, Vol. 1, No. 1, pp. 30-43.

Arad, S., Hanson, M. A. and Schneider, R. J. (1997). A framework for the study of relationships between organizational characteristics and organizational innovation. The Journal of Creative Behavior, Vol. 31, No. 1, pp. $42-58$.

Armstrong, M. (1995). A Handbook of Personnel Management Practice (5th ed.). London: Kogan Page.

Barret, R. (1997). Liberating the corporate soul. HR Focus, Vol. 74, No. 4, pp. 15-16.

Bresnahan, J. (1997). The elusive muse. CIO, Vol. 11, No. 2, pp. 50-6.

Brodtrick, O. (1997). Innovation as reconciliation of competing values. Optimum, Vol. 27, No. 2, pp. 1-4.

Buchanan, M., Iyer, R. and Karl, C. A. (1999). The case study in business research. Global Research Business. Available http://www.globalresearchbusiness.com.

CIMA Study Text (1996). Organisational Management and Development (3rd ed.). London: BPP Publishing.

Covey, S. R. (1993). Innovation at four levels. Executive Excellence, Vol. 10, No. 9, pp. 3-5.

Denzin, N. K. and Lincoln, Y. S. (2003). Introduction. The discipline and practice of qualitative research. In Denzin, N. K. and Lincoln, Y. S. (Eds), The Landscape of Qualitative Research (pp.1-46). Thousand Oaks, CA: Sage Publications.

Deshpandé, R., and Webster, F. E. (1989). Organizational culture and marketing: defining the research agenda. Journal of Marketing, Vol. 53, pp. 3-15.

Filipczak, B. (1997). It takes all kinds: creativity in the workforce. Training, Vol. 34 No.5, pp.32-40.

Frohman, M. and Pascarella, P. (1990). Achieving purpose-driven innovation. Industry Week, No. 239, pp. 20-4.

Furnham, A. and Gunter, B. (1993). Corporate Assessment: Auditing a Company's Personality. London: Routledge.

Glaser, B. and Strauss, A. (1967). The Discovery of Grounded Theory. Chicago: Aldine.

Guion, R. M. (2002). Validity and reliability. In S. G. Rogelberg (Ed.), Handbook of research methods in industrial and organizational psychology (pp. 57-76).

Hatch, M. J. (1993). The dynamics of organizational culture. Academy of Management Review, Vol. 18, No. 4, pp. 657-93.

Herriott, R. E. and Firestone, W. A. (1983). Multisite Qualitative Policy Research: Optimizing Descriptions and Generalizability. Educational Researcher, Vol. 12, No. 2, pp. 14-19.

Hofstede, G. (1998). Attitudes, values and organizational culture: disentangling the concepts. Organization Studies, Vol. 19, No. 3, pp. 477-92.

Johnson, M. M. (1996). Finding creativity in a technical organization. Research Technology Management, Vol. 3a, No. 5, pp. 9-11.

Judge, W. Q., Fryxell, G. E. and Dooley, R. S. (1997). The new task of R\&D management: creating goal-directed communities for innovation. California Management Review, Vol. 39, No. 3, pp. 72-85.

Khalil, O. E. M. (1996). Innovative work environments: the role of information technology and systems. SAM Advanced Management Journal, Vol. 61, No. 3, pp. 32-6.

Li, L. X. and Collier, D. A. (2000). The role of technology and quality on hospital financial performance an exploratory analysis. International Journal of Service Industry Management, Vol. 11, No. 3, pp. 202.

Lock, E. A. and Kirkpatrick, S. A. (1995). Promoting creativity in organizations. In Ford, C. M., and Gioia, D. A. (Eds), Creative Action in Organizations: Ivory Tower Visions \& Real World Voices (pp.115-120). London: Sage. 
Martin, P. Y. and Turner, B. A. (1986). Grounded theory and organizational research. Journal of Applied Behaviorial Science, 22, 2, pp. 141-157.

Martins, N. (1987). Organisasiekultuur in 'n finansiële instelling/Organisational culture in a financial institution (DPhil thesis). Pretoria: University of Pretoria.

Martins, N. (1997). Elandsrand Gold-mine: organisational culture survey. Johannesburg.

Martins, E. C. (2000). Die invloed van organisasiekultuur op kreatiwiteit en innovasie in ' $n$ universiteitbiblioteek/ The influence of organisational culture on creativity and innovation in a university library (MInf dissertation). Pretoria: University of South Africa.

McDonald, R. E. and Srinivasan, N. (2004). Technological innovations in hospitals: what kind of competitive advantage does adoption lead to? International Journal of Technology Management, Vol. 28, No. 1, p. 103.

Nÿstrom, H. (1990). Organizational innovation. In West, M. A., and Farr, J. L. (Eds), Innovation and Creativity at Work: Psychological and Organizational Strategies (pp. 143-161). Wiley, Chichester.

Patton, M. Q. (1987). How to Use Qualitative Methods in Evaluation. California: Sage Publications, Inc.

Pheysey, D. C. (1993). Organisational Cultures: Types and Transformations. London: Routledge.

Pringle, H., and Thompson, M. (1999). Brand Spirit: How Cause Related Marketing Builds Brands (p.31). Chichester, John Wiley.

Ramakrishnan, R. (2005). Operations assessment of hospitals in the Sultanate of Oman. International Journal of Operations \& Production Management, Vol. 25, No. 1, pp. 39-55.

Rauner, M. S. and Heidenberger, K. (2002). Scope and role of strategic technology management in hospitals: the case of Vienna, Austria. International Journal of Healthcare Technology and Management, Vol. 4, No. 3/4, p. 239.

Read, W. H. (1996). Managing the knowledge-based organization: five principles every manager can use. Technology Analysis and Strategic Management, Vol. 8, No. 3, pp. 223-232.

Robbins, S. P. (1996). Organizational Behavior: Concepts, Controversies, Applications (7th ed.). Englewood Cliffs, NJ: Prentice-Hall.

Robbins, S. P. (1997). Essentials of Organizational Behavior (5th ed.). Upper Saddle River, NJ: Prentice-Hall.

Robson, C. (1993). Real world research: A resource for social scientists and practitioner-researchers. Oxford: Blackwell.

Samaha, H. E. (1996). Overcoming the TQM barrier to innovation. HR Magazine, Vol. 41, No. 6, pp. 145-149.

Schein, E. H. (1985). Organizational Culture and Leadership. San Francisco, CA: Jossey-Bass.

Shattow, M. (1996). Out of the blue. Electric Perspectives, 44-54, Vol. 21, No. 3.

Syrett, M., and Lammiman, J. (1997). The art of conjuring ideas. Director, Vol. 50, No. 9, pp. 48-54.

Tellis, W. (1997). Application of a case study methodology. Qualitative Report, Vol 3, No. 3.

Tesluk, P. E., Faar, J. L. and Klein, S. R. (1997). Influences of organizational culture and climate on individual creativity. The Journal of Creative Behavior, Vol. 31, No. 1, pp. 21-41.

Travers, M. (2001). Qualitative Research Through Case Studies (Chapter 1). London: Sage.

Trice, H. M. and Beyer, J. M. (1993). The Culture of Work Organizations. Englewood Cliffs, NJ: Prentice-Hall.

Tushman, M. L. and O’Reilly, C. A. III (1997). Winning through Innovation: A Practical Guide to Leading Organizational Change and Renewal. Boston, MA: Harvard Business School Press.

West, M. A. and Farr, J. L. (1990). Innovation at work. In West, M. A., and Farr, J. L. (Eds), Innovation and Creativityat Work: Psychological and Organizational Strategies (pp.3-13). Wiley, Chichester.

Yin, R. K. (2002). Case Study Research Design and Method. California, USA: Sage Publications. 
Table 1. Overview of the sample

\begin{tabular}{lccc}
\hline Hospital code & Number of employees & Level of technology & Performance \\
\hline H1 & 164 & H & M \\
H2 & 262 & M & H \\
H3 & 115 & L & L \\
H4 & 328 & H & H \\
H5 & 197 & M & M \\
H6 & 131 & L & M \\
H7 & 280 & M & H \\
H8 & 175 & H & M \\
\hline
\end{tabular}

Key: $\mathrm{H}=$ High, $\mathrm{M}=$ Medium, $\mathrm{L}=$ Low

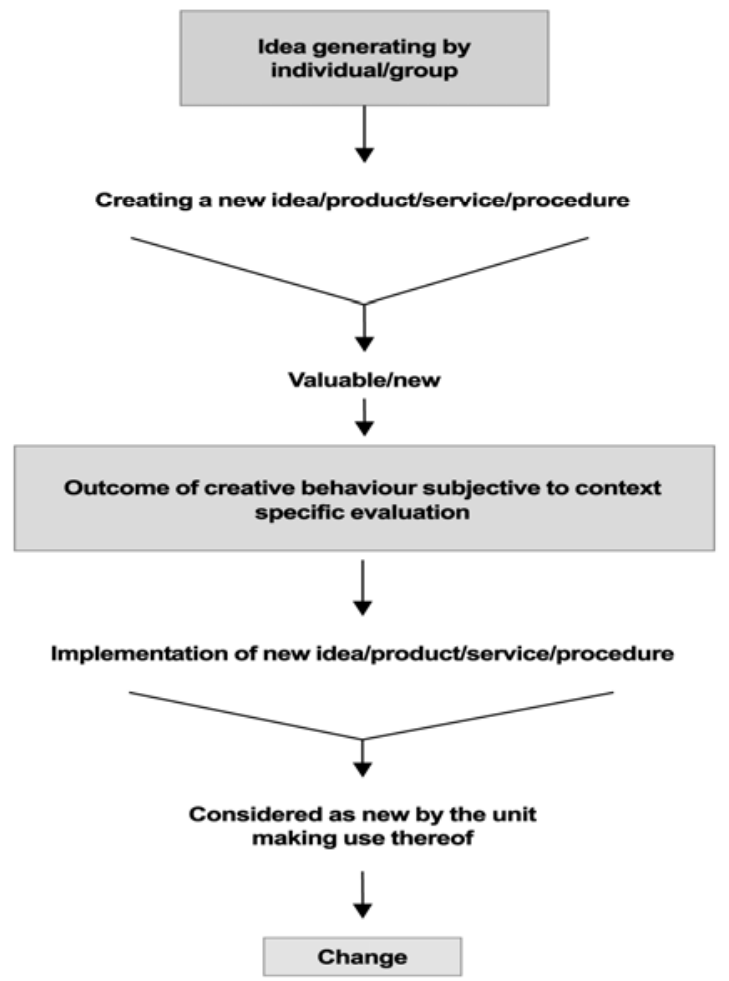

Figure 1. Defining innovation

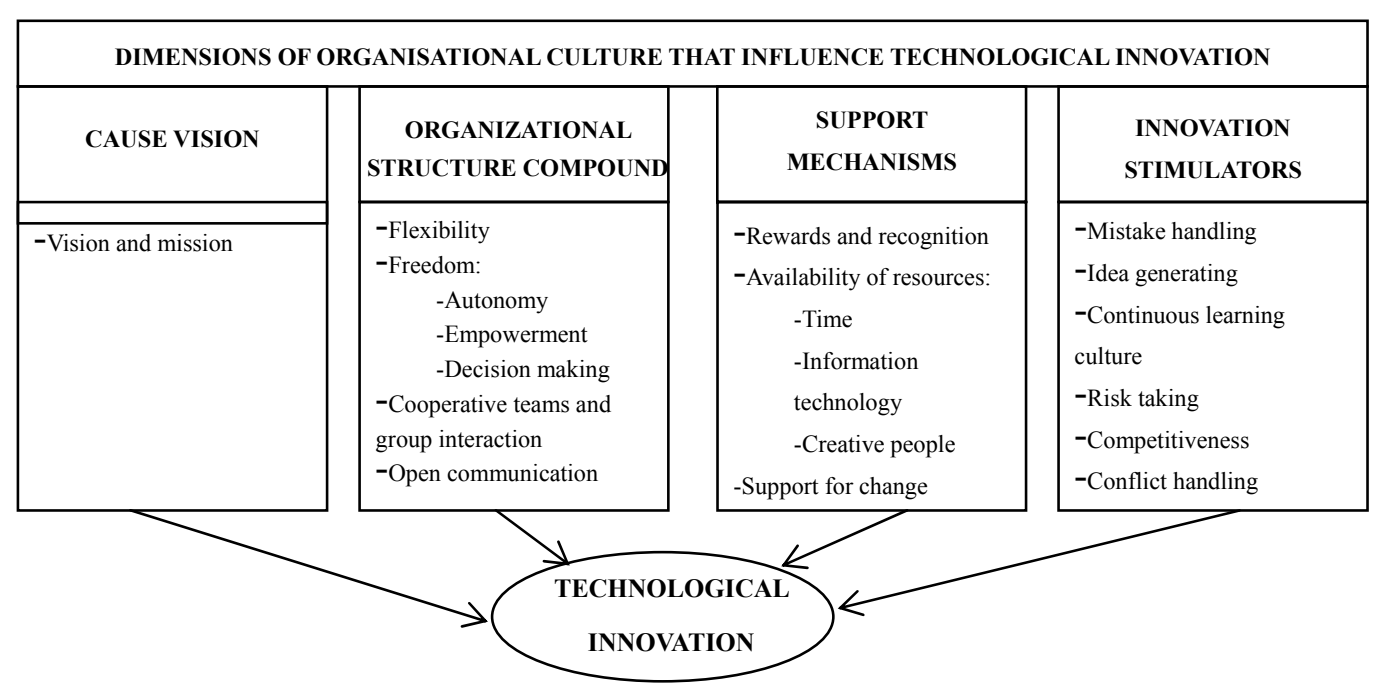

Figure 2. Influence of organizational culture on technological innovation 